\title{
DETECÇÃO ATRAVÉS DE REAÇÃO EM CADEIA PELA POLIMERASE EM TEMPO REAL SEGUIDA DE ANÁLISE DE ALTA RESOLUÇÃO DE CURVAS DE DISSOCIAÇÃO (qPCR-HRM) DE PROTOZOÁRIOS PARASITOS (APICOMPLEXA: SARCOCYSTIDAE) EM AMOSTRAS DE EMBUTIDOS DE ORIGEM SUÍNA
}

\author{
Jadson Nascimento Borges ${ }^{1}$; Kathleen de Almeida Ferreira ${ }^{2}$; Taise Cristina Santa \\ Barbara Silva Queiroz ${ }^{3}$; Caroline Araújo da Silva ${ }^{4}$; Aristeu Vieira da Silva ${ }^{5}$ \\ 1. Bolsista PIBIC/CNPq, Graduando em Bacharelado em Ciências Biológicas, Universidade Estadual de Feira de Santana, e- \\ mail: jadsonnascimento@outlook.com \\ 2. Bolsista PIBIC/CNPq, Graduanda em Bacharelado em Ciências Biológicas, Universidade Estadual de Feira de Santana, e- \\ mail: kathleen_fsa@hotmail.com \\ 3. Bolsista PIBIC/FAPESB, Graduanda em Bacharelado em Ciências Biológicas, Universidade Estadual de Feira de Santana, \\ e-mail: taii.cristina@hotmail.com \\ 4. Bolsista PIBIC/FAPESB, Graduanda em Bacharelado em Ciências Biológicas, Universidade Estadual de Feira de Santana, \\ e-mail: carol.adp@hotmail.com \\ 5. Orientador, Departamento de Ciências Biológicas, Universidade Estadual de Feira de Santana - Bolsista de Produtividade \\ em Pesquisa CNPq, e-mail: aristeuvsilva@uefs.br
}

PALAVRAS-CHAVE: Sarcocystidae; qPCR-HRM; embutidos.

\section{INTRODUÇÃO}

A família Sarcocystidae compreende os parasitos dos gêneros Toxoplasma, Neospora, Sarcocystis, Hammondia, Besnoitia (Irvine; Walker; Friedrichs, 2016) e Cystoisospora spp. (Samarasinghe; Johnson; Ryan, 2008). Os principais parasitos da Família Sarcocystidae que infectam humanos são o Sarcocystis spp. e o Toxoplasma gondii.

Existem duas espécies de Sarcocystis que tem o homem como hospedeiro definitivo, $S$. hominis e $S$. suihominis, estes possuem como hospedeiros intermediários, respectivamente, bovinos e suínos. Sarcocystis possuem um ciclo de vida heteroxênico, ou seja, com dois hospedeiros. Hospedeiros intermediários são infectados pela ingestão de oocistos ou esporocistos livres em alimentos ou água contaminados com fezes dos hospedeiros definitivos e estes completam o ciclo ao consumir cistos intramusculares de hospedeiros intermediários (Davies et al., 2011). Em seres humanos, geralmente a infecção por Sarcocystis causa sintomas auto limitantes como diarreias, náuseas, vômitos, dor abdominal e cólicas (Neves, 2012). Em animais de produção a infecção por Sarcocystis é mais dramática podendo causar sintomas variados (Carrigan, 1986), resultando também na diminuição da produção leiteira e da carne e abortamentos (Fayer; Johnson; Lunde, 1976).

Os hospedeiros definitivos do $T$. gondii são os felídeos e seus hospedeiros intermediários compreendem vários animais homeotérmicos, domésticos e silvestres, incluindo o homem. O T. gondii possui um ciclo de vida do tipo heteroxênico facultativo, ou seja, os hospedeiros definitivos podem se infectar pelas diferentes formas infectantes apresentadas pelo parasito durante seu ciclo de vida, e os diversos outros animais que podem se infectar pelo parasito não sustentam seu ciclo sexual, sendo considerados hospedeiros intermediários, estes se infectam pela ingestão de oocistos eliminados nas fezes de felinos, ingestão de cistos teciduais, ou por via congênita. Em humanos a maioria das infecções por Toxoplasma gondii são assintomáticas, porém muitos indivíduos imunodeprimidos desenvolvem encefalite aguda culminando em óbito (Rey, 2008), em infecções intrauterinas é comum sequelas como retinocoroidite, encefalomielite e hidrocefalia ou microcefalia (Voge et al., 2003). Em animais 
de produção este parasito é responsável por severas perdas, pois causam, entre outros males, o abortamento das crias (Bowman, 2006).

O estudo aqui apresentado objetivou a detecção de protozoário parasitos pertencentes a família Sarcocystidae em tecidos de origem suína (Sus scrofa) comercializados na forma de embutidos em feiras livres do munícipio de Feira de Santana, BA, por meio da técnica de reação em cadeia da polimerase em tempo real (qPCR) seguida da análise de alta resolução de curvas de dissociação (HRM).

\section{MATERIAL E MÉTODOS}

Foram utilizadas alíquotas de 74 amostras de tecidos de embutidos coletadas em feiras livre do município Feira de Santana-BA coletadas em um trabalho anterior. As amostras permaneceram congeladas a $-20^{\circ} \mathrm{C}$ até o momento da extração do ácido desoxirribonucleico (DNA).

A extração de DNA foi realizada utilizando o kit PureLink® Genomic DNA de acordo com as instruções do fabricante.

Para detecção e amplificação de DNA de Sarcocystidae foram utilizados oligonucleotídeos para uma sequência do gene 18S do rRNA. A análise de alta resolução das curvas de dissociação (HRM) para Sarcocystidae foi padronizada para diferenciar Toxoplasma gondii, Sarcocystis neurona, Neospora caninum e Cryptosporidium parvum (Fehlberg, 2016).

A HRM foi realizada na plataforma AB7500 Fast (Life Technologies®) utilizando MeltDoctor ${ }^{\circledR}$ como agente intercalante. Para identificação da temperatura de melting $(\mathrm{Tm}) \mathrm{de}$ cada parasito, o DNA extraído foi amplificado individualmente em uma reação de $20 \mu \mathrm{L}$, contendo $10 \mu \mathrm{L}$ MeltDoctor HRM Master Mix (Life Technologies $\left.{ }^{\circledR}\right), 1,2 \mu \mathrm{L}$ (1 pmol) de cada oligonucleotídeo iniciador (senso e anti-senso), $2 \mu \mathrm{L}$ da amostra com $20 \mathrm{ng}$ de DNA/ $\mu \mathrm{l}$ e água ultrapura qsp $20 \mu \mathrm{l}$. As reações de PCR foram realizadas em 35 ciclos de $95^{\circ} \mathrm{C}$ por $15 \mathrm{~s} \mathrm{e} 60^{\circ} \mathrm{C}$ por 1 min e uma rampa HRM foi gerada através dos dados de aquisição de fluorescência entre as temperaturas de $72^{\circ} \mathrm{C}$ a $88^{\circ} \mathrm{C}$. Todas as amostras foram avaliadas em duplicata.

\section{RESULTADOS E DISCUSSÃO}

Das 74 amostras de DNA extraídas de embutidos de suínos analisadas, quatro (5,41\%; IC95\%: 1,49-13,27\%) amplificaram sequências de organismos diferentes dos utilizados no controle na HRM.

A utilização da PCR para amplificação da região $18 \mathrm{~S}$ do rRNA para a detecção de parasitos da família Sarcocystidae tem sido amplamente relatada na literatura científica. Por este motivo não consideramos que o pequeno número de amostras amplificadas esteja relacionado com uma baixa sensibilidade da sequência alvo selecionada.

Das amostras analisadas em Yazd, Irã (Hajimohammadi et al., 2014), 77,9\% foram positivas para Sarcocystis spp. No Egito do total de amostras analisadas, 53\% e 12,3\% estavam infectadas por S. fusiformis e S. buffalonis, respectivamente (El-Seify, 2014). No norte da Índia pela PCR convencional $72,8 \%$ das amostras foram positivas, enquanto pela qPCR houve positividade em $76,4 \%$ (Kaur et al., 2015). No Irã, houve sucesso na detecção de DNA com $66,7 \%, 20 \%$ e $13,3 \%$ das amostras sendo compatíveis com as espécies $S$. gigantea, S. moulei e Sarcocystis spp., respectivamente (Kalantari et al., 2016). 
A baixa frequência de amostras amplificadas pode estar relacionada com um fator de diluição, tendo em vista que inicialmente contávamos com uma amostra de cerca de $250 \mathrm{~g}$, da qual foram separados, aleatoriamente, $25 \mathrm{~g}$ de tecido e destes, após homogeneização com salina, apenas $200 \mu \mathrm{L}$ procederam para a extração de DNA, o que pode ter reduzido consideravelmente a chance de formas parasitárias serem submetidas a extração de DNA.

\section{CONSIDERAÇÕES FINAIS}

A PCR-HRM não detectou a presença de DNA compatível com Toxoplasma gondii ou Sarcocystis spp. em amostras de embutidos de origem suína, entretanto quatro amostras tiveram sequências amplificadas, as quais serão submetidas a sequenciamento para determinação do gênero ou espécie envolvida.

\section{REFERÊNCIAS}

BOWMAN, D. D. Parasitologia veterinária de Georgis. 8. ed. [s.1.] Manole, 2006.

CARRIGAN, M. J. An outbreak of sarcocystosis in dairy cattle. Aus Vet J, v. 63, n. 1, p. 2224, 1 jan. 1986.

DAVIES, J. L. et al. Fatal Hepatic Sarcocystosis in a Captive Black Bear (Ursus Americanus) Associated with Sarcocystis Canis-Like Infection. J Vet Diagn Invest, v. 23, n. 2, p. 379-383, 1 mar. 2011.

EL-SEIFY. Molecular Characterization of Sarcocytis fusiformis and Sarcocystis buffalonis Infecting Water Buffaloes (Bubalus bubalis) from Egypt. American Journal of Animal and Veterinary Sciences, v. 9, n. 2, p. 95-104, 1 fev. 2014.

FAYER, R.; JOHNSON, A. J.; LUNDE, M. Abortion and other signs of disease in cows experimentally infected with Sarcocystis fusiformis from dogs. The Journal of Infectious Diseases, v. 134, n. 6, p. 624-628, dez. 1976.

HAJIMOHAMMADI et al. Prevalence and species identification of Sarcocystis in raw hamburgers distributed in Yazd, Iran using PCR-RFLP. Journal of food quality and hazards control, v. 1, n. 1, p. 15-20, 15 mar. 2014.

IRVINE, K. L.; WALKER, J. M.; FRIEDRICHS, K. R. Sarcocystid organisms found in bile from a dog with acute hepatitis: a case report and review of intestinal and hepatobiliary Sarcocystidae infections in dogs and cats. Vet Clin Path, v. 45, n. 1, p. 57-65, 1 mar. 2016.

KALANTARI, N. et al. Molecular Analysis of Sarcocystis Spp. Isolated from Sheep (Ovis aries) in Babol Area, Mazandaran Province, Northern Iran. Iran J Parasitol, v. 11, n. 1, p. 73 80, 2016.

KAUR, M. et al. Pervasive Environmental Contamination with Human Feces Results in High Prevalence of Zoonotic Sarcocystis Infection in Pigs in the Punjab, India. J Parasitol, v. 102, n. 2, p. 229-232, 20 nov. 2015.

NEVES, D. P. Parasitologia humana. São Paulo: Atheneu, 2012.

REY, L. Parasitologia: parasitos e doenças parasitárias do homem nos trópicos ocidentais. 3. ed. Rio de Janeiro: Guanabara Koogan, 2008.

SAMARASINGHE, B.; JOHNSON, J.; RYAN, U. Phylogenetic analysis of Cystoisospora species at the rRNA ITS 1 locus and development of a PCR-RFLP assay. Exp Parasitol, v. 118, n. 4, p. 592-595, abr. 2008.

VOGE, M. et al. Markell and Voge Parasitologia médica. 8. ed. Rio de Janeiro: GuanabaraKoogan, 2003. 